\title{
$\mu$ Opioid Receptor Agonism for L-DOPA-Induced Dyskinesia in Parkinson's Disease
}

\author{
${ }^{\circ}$ Erwan Bezard, ${ }^{1,2,3,4}$ Qin Li, ${ }^{3,4}$ Heather Hulme, ${ }^{5,6}$ Elva Fridjonsdottir, ${ }^{5}$ Anna Nilsson, ${ }^{5,6}$ Elsa Pioli, ${ }^{3}$ \\ Per E. Andren, ${ }^{5,6}$ and Alan R. Crossman ${ }^{3}$ \\ ${ }^{1}$ Institut des Maladies Neurodégénératives, Université de Bordeaux, Unité Mixte de Recherche 5293, Bordeaux, 33000, France, ${ }^{2}$ Institut des \\ Maladies Neurodégénératives, Centre National de la Recherche Scientifique, Unité Mixte de Recherche 5293, Bordeaux, 33000, France, ${ }^{3}$ Motac \\ Neuroscience, Manchester, M15 6WE, United Kingdom, ${ }^{4}$ Institute of Lab Animal Sciences, China Academy of Medical Sciences, Beijing, 100021, \\ China, ${ }^{5}$ Medical Mass Spectrometry Imaging, Department of Pharmaceutical Biosciences, Uppsala University, Uppsala, SE-75124, Sweden, and \\ ${ }^{6}$ Science for Life Laboratory, National Resource for Mass Spectrometry Imaging, Uppsala University, Uppsala, SE-75124, Sweden
}

Parkinson's disease (PD) is characterized by severe locomotor deficits and is commonly treated with the dopamine precursor L-DOPA, but its prolonged usage causes dyskinesias referred to as L-DOPA-induced dyskinesia (LID). Several studies in animal models of PD have suggested that dyskinesias are associated with a heightened opioid cotransmitter tone, observations that have led to the notion of a LID-related hyperactive opioid transmission that should be corrected by $\mu$ opioid receptor antagonists. Reports that both antagonists and agonists of the $\mu$ opioid receptor may alleviate LID severity in primate models of PD and LID, together with the failure of nonspecific antagonist to improve LID in pilot clinical trials in patients, raises doubt about the reliability of the available data on the opioid system in PD and LID. After in vitro characterization of the functional activity at the $\mu$ opioid receptor, we selected prototypical agonists, antagonists, and partial agonists at the $\mu$ opioid receptor. We then showed that both oral and discrete intracerebral administration of a $\mu$ receptor agonist, but not of an antagonist as long thought, ameliorated LIDs in the gold-standard bilateral 1-methyl-4-phenyl-1,2,3,6-tetrahydropyridinelesioned female macaque model of PD and LID. The results call for a reappraisal of opioid pharmacology in the basal ganglia as well as for the development of brain nucleus-targeted $\mu$ opioid receptor agonists.

Key words: dyskinesia; MALDI; $\mu$; opioid; primate

Significance Statement

$\mu$ opioid receptors have long been considered as a viable target for alleviating the severity of L-DOPA-induced hyperkinetic side effects, induced by the chronic treatment of Parkinson's disease motor symptoms with L-DOPA. Conflicting results between experimental parkinsonism and Parkinson's disease patients, however, dampened the enthusiasm for the target. Here we reappraise the pharmacology and then demonstrate that both oral and discrete intracerebral administration of a $\mu$ receptor agonist, but not of an antagonist as long thought, ameliorates LIDs in the gold-standard bilateral 1-methyl-4-phenyl1,2,3,6-tetrahydropyridine-lesioned macaque model of Parkinson's disease, calling for a reappraisal of the opioid pharmacology as well as for the development of brain nucleus-targeted $\mu$ receptor agonists.

Received Mar. 15, 2020; revised July 12, 2020; accepted July 15, 2020.

Author contributions: E.B., P.E.A., and A.R.C. designed research; E.B., Q.L., H.H., E.F., A.N., E.P., and P.E.A. performed research; E.B. and P.E.A. analyzed data; E.B. wrote the first draft of the paper; E.B., E.P., P.E.A., and A.R.C. edited the paper; E.B. wrote the paper.

E.P. and Q.L. are employees of Motac Neuroscience Ltd, a contract research organization. E.B. and A.R.C. own equity stakes in Motac Holdings Ltd and receive consultancy payments from Motac Neuroscience Ltd. The remaining authors declare no competing financial interests.

This work was supported by Michael J. Fox Foundation target validation grant to E.B., LABEX BRAIN Grant ANR-10-LABX-43 to E.B., Swedish Research Council Grant 2018-03320 to P.E.A., Swedish Brain Foundation Grant F02018-0292 to P.E.A., Swedish Foundation for Strategic Research Grant RIF14-0078 to P.E.A., and Science for Life Laboratory grant to P.E.A. The funders had no role in study design, data collection and analysis, decision to publish, or preparation of the manuscript. We thank Curis Inc for the gift of ADC02265510 and ADC-02520849; and H. Li, Y. Chen, W. Chu, W. Li, and R. Xing for expert experimental support. Correspondence should be addressed to Erwan Bezard at erwan.bezard@u-bordeaux.fr.

https://doi.org/10.1523/JNEUROSCI.0610-20.2020

Copyright $\odot 2020$ the authors

\section{Introduction}

The reduced movement repertoire of Parkinson's disease (PD) is due primarily to degeneration of nigrostriatal dopamine neurones. Levodopa (L-DOPA) restores dopaminemediated modulation, which successfully relieves motor symptoms of PD. However, the repeated intake of L-DOPA leads to severe side effects known as L-DOPA-induced dyskinesia (LID) (Bastide et al., 2015). The neural mechanisms that underlie LID in PD are still not entirely clear, although important advances have been made.

Dyskinesia has been associated with a sequence of events that include pulsatile stimulation of dopamine receptors, downstream changes in proteins and genes, and abnormalities in 
nondopamine transmitters (Bezard et al., 2001a; Bastide et al., 2015). Of these, opioid receptor neurotransmission is of particular interest, as opioids are cotransmitters that modulate basal ganglia function, and changes in opioid transmission, occur in dyskinetic PD patients and animal models (Cenci et al., 1998; Henry et al., 1999, 2003; Morissette et al., 1999; Tel et al., 2002; Aubert et al., 2007; Marti et al., 2012; Mercatelli et al., 2020). While ISH studies showed that striatal peptidergic precursor expression consistently correlates with LID severity, few studies have focused on the actual peptides being processed from these precursors, that is, Met- and Leu-enkephalins, deriving from preproenkephalin $\mathrm{A}$, and dynorphin $\mathrm{A}$ and $\mathrm{B}$ deriving from preproenkephalin B (Hanrieder et al., 2011; Bourdenx et al., 2014). The opioid-like neuropeptide nociceptin/orphanin FQ and its receptor (NOP receptor) also contribute to LID (Mercatelli et al., 2020). A similarly scarce number of studies have focused on LID-related changes in opioid receptor expression or binding in the basal ganglia (i.e., $\mu, \kappa$, and $\delta$ receptors) (Piccini et al., 1997; Johansson et al., 2001; Aubert et al., 2007). The striking negative correlation between $\mu$ opioid receptor binding in the internal segment of the globus pallidus (GPi) of dyskinetic 6-OHDAlesioned rats (Johansson et al., 2001) and dyskinetic 1methyl-4-phenyl-1,2,3,6-tetrahydropyridine (MPTP)-treated macaques (Aubert et al., 2007) and the increased presence of $\mu$ opioid receptor ligands in the same dyskinetic primate GPi (Bourdenx et al., 2014) supports the notion of hyperactive opioid transmission in LID that should be corrected by $\mu$ opioid receptor antagonists.

The demonstration that $\mu$ opioid receptor antagonists efficiently reduce LID in nonhuman primate (NHP) models without affecting the anti-parkinson action of L-DOPA (Henry et al., 2001; Koprich et al., 2011; Potts et al., 2015) supported that hypothesis. That morphine itself was, however, also shown to moderately alleviate LID in NHPs (Samadi et al., 2004) cast doubt on the supposed functional activity of classic $\mu$ opioid receptor ligands. The failure of the non-subtype-selective opioid receptor antagonists naltrexone and naloxone in clinical trials (Rascol et al., 1994; Fox et al., 2004) further complicated our understanding of the opioid system in basal ganglia pathophysiology (Parent et al., 1995).

Although one may hypothesize that subtype-selective agents would have a better clinical outcome, recent peptidomic-based results showing that regulation of peptidergic processing is highly structure-specific (Bourdenx et al., 2014), suggesting that something more complex than a simple subtype-selective agent may be required to fully reverse the effects of the complex changes that occur in basal ganglia neuropeptide transmission in LID.

In the current study, we show that discrete intracerebral administration of a $\mu$ receptor agonist, but not of an antagonist, ameliorates LIDs in the gold-standard bilateral MPTP-lesioned macaque model of PD and LID, calling for a reappraisal of the pharmacology as well as for the development of brain nucleustargeted compounds as potential therapies.

\section{Materials and Methods}

In vitro pharmacology. Binding affinity of the new chemical entities was calculated from the inhibition of the binding of a radioactively labeled ligand detected by scintillation method conducted on human recombinant $\mu$ opioid receptor-expressing HEK-293 cells exposed to 0.5 $\mathrm{nM}$ of $\left[{ }^{3} \mathrm{H}\right] \mathrm{DAMGO}$ (nonspecific binding defined with $10 \mu \mathrm{M}$ naloxone), on human recombinant $\kappa$ opioid receptor-expressing Chinese hamster ovary (CHO) cells exposed to $1 \mathrm{~nm}$ of $\left[{ }^{3} \mathrm{H}\right] \mathrm{U} 69593$ (nonspecific binding defined with $10 \mu \mathrm{m}$ naloxone), and on human recombinant $\delta$ opioid receptor-expressing $\mathrm{CHO}$ cells exposed to $0.5 \mathrm{~nm}$ of $\left[{ }^{3} \mathrm{H}\right] \mathrm{DADLE}$ (nonspecific binding defined with $10 \mu \mathrm{m}$ naltrexone) (CEREP). Furthermore, a large screen was conducted using the same technique at one dose on 80 GPCRs, ions channels, and neurotransmitter transporters (CEREP). It did not show any significant binding on other targets (data not shown).

New chemical entities were tested from $1 \times 10^{-7}$ to $1 \times 10^{-10} \mathrm{M}$ for their functional activity in a cAMP homogeneous time-resolved fluorescence assay conducted on human recombinant $\mu$ opioid receptorexpressing $\mathrm{CHO}$ cells (CEREP). Agonism was tested alone while the $\mu$ opioid receptor agonist DAMGO $\left(\mathrm{EC}_{50}=1.9^{-9} \mathrm{M}\right)$ was used as the comparator. Antagonist activity was tested in the presence of $20 \mu \mathrm{M}$ of DAMGO, whereas the $\mu$ opioid receptor antagonist CTOP $\left(\mathrm{IC}_{50}=1.4^{-8}\right.$ м) was used as the comparator. Drugs were incubated at $37^{\circ} \mathrm{C}$ for $10 \mathrm{~min}$. The results are expressed as a percent of control agonist response for defining agonist activity and as a percent inhibition of control agonist response obtained in the presence of the test compounds for antagonist activity.

Animals. Experiments were performed in accordance with the European Union directive of September 22, 2010 (2010/63/EU) on the protection of animals used for scientific purposes in an Association for Assessment and Accreditation of Laboratory Animal Care-accredited facility following acceptance of study design by the Institutional Animal Care and Use Committee of the Institute of Lab Animal Science (Chinese Academy of Science, Beijing, China). The tissues used in the present work were sourced from an experimental brain bank (females only) used on several previous occasions, the experimental conditions of which have been described previously in great details (Rylander et al., 2010; Santini et al., 2010; Shariatgorji et al., 2014; Engeln et al., 2015; Napolitano et al., 2017; Rojo-Bustamante et al., 2018; Mellone et al., 2019; Eshraghi et al., 2020). Briefly, macaque monkeys received daily MPTP hydrochloride injections $(0.2 \mathrm{mg} / \mathrm{kg}$, i.v. $)$ until parkinsonian signs appeared. Once PD motor signs were stable, while some animals remained untreated (MPTP), some were treated twice daily with an individually titrated dose of L-DOPA that provided maximum reversal of parkinsonian motor signs for 4-5 months until dyskinesia stabilized (Madopar, L-DOPA/carbidopa, 4:1 ratio; range, $9-17 \mathrm{mg} / \mathrm{kg}$ ). At the end of the experiment, all animals were killed by sodium pentobarbital overdose $(150 \mathrm{mg} / \mathrm{kg}$, i.v.) $1 \mathrm{~h}$ after the last dose of vehicle or L-DOPA (i.e., at peak of antiparkinsonian effect), and the brains were removed quickly after death. Each brain was bisected along the midline, and the two hemispheres were immediately frozen by immersion in isopentane $\left(-45^{\circ} \mathrm{C}\right)$ and then stored at $-80^{\circ} \mathrm{C}$.

Three additional female macaques (Macaca fascicularis, Xierxin) were housed in individual primate cages allowing visual contact and interactions with monkeys housed in adjacent cages, under controlled conditions. Food and water were available ad libitum. Animal care was supervised daily by veterinarians skilled in the health care and maintenance of NHPs.

Model preparation. The MPTP intoxication protocol, the chronic LDOPA treatment, the clinical assessments, the terminal procedure, and the characterization of the extent of nigrostriatal denervation were conducted as previously published (Bezard et al., 2003; Aubert et al., 2005; Ahmed et al., 2010; Fasano et al., 2010; Santini et al., 2010; Porras et al., 2012). Animals were first rendered parkinsonian with MPTP-hydrochloride $(0.2 \mathrm{mg} / \mathrm{kg}$, i.v., Sigma Millipore) dissolved in saline (Bezard et al., 2003; Aubert et al., 2005; Ahmed et al., 2010; Fasano et al., 2010; Santini et al., 2010). Daily (9:00 A.M.) assessment of parkinsonism was performed in home cages for $30 \mathrm{~min}$ by 2 blinded observers using a validated rating scale (Bezard et al., 2001b) assessing tremor, general level of activity, body posture (flexion of spine), vocalization, freezing and frequency of arm movements, and rigidity (for each upper limb). Following stabilization of the MPTP-induced syndrome (3 months), animals received twice-daily $20 \mathrm{mg} / \mathrm{kg}$ L-DOPA p.o. for 3 months and developed severe and reproducible dyskinesia, presenting choreic-athetoid (characterized by constant writhing and jerking motions), dystonic, and sometimes ballistic movements (large-amplitude flinging, flailing movements). Once animals were stably 
dyskinetic, striatal and pallidal stereotactic cannulation was conducted under isoflurane anesthesia using the Horsley-Clarke stereotaxic technique coupled with ventriculography as previously described (Ahmed et al., 2010; Fasano et al., 2010; Porras et al., 2012). A stereotaxic atlas (François et al., 1996) was used for precise adjustment before bilateral insertion of stainless-steel guide cannulae (Plastics One; 22-gauge, $11 \mathrm{~mm}$ length) into the skull to allow access to the putamen (AP $0 \mathrm{~mm}, \mathrm{~L} 10 \mathrm{~mm}, \mathrm{D} 3 \mathrm{~mm}$ ) and GPi (AP $-3 \mathrm{~mm}, \mathrm{~L} 7 \mathrm{~mm}, \mathrm{D}-1 \mathrm{~mm}$ ) (Bezard et al., 1997). Guide cannulae were secured to the skull with stainless-steel screws and dental acrylic cement (Bezard et al., 1997).

Matrix-assisted laser desorption/ionization mass spectrometry imaging (MALDI-MSI) imaging. Mapping the abundance and distributions of neuropeptides within brain regions remained a big challenge until MALDI-MSI was developed. This label-free technique is used to map distributions and relative quantities of molecules in tissue sections. Because MALDI-MSI is not limited by molecular labeling, thousands of molecules can be imaged in a single experiment, so it is suitable for simultaneously mapping multiple neuropeptides in a single tissue section (Shariatgorji et al., 2014, 2019; Hulme et al., 2020).

The frozen brains of the brain bank were sectioned at a thickness of $12 \mu \mathrm{m}$ on a cryostat and the sections were thaw-mounted onto conductive, indium tin oxide-coated glass slides (Bruker Daltonics). The slides were stored at $-80^{\circ} \mathrm{C}$. Before analysis, the slides were brought to room temperature while drying under a stream of nitrogen and dried further in a desiccator for $30 \mathrm{~min}$. The slides were washed in $45 \mathrm{ml}$ of chloroform for $35 \mathrm{~s}$ and dried immediately in a desiccator for $15 \mathrm{~min}$.

The matrix used was 2,5-dihydroxybenzoic acid at a concentration of $25 \mathrm{mg} / \mathrm{ml}$ in $50 \%$ acetonitrile, $50 \%$ water, and $0.2 \%$ trifluoroacetic acid. Matrix application was performed using a robotic matrix sprayer (TM sprayer, HTX Technologies), at $85^{\circ} \mathrm{C}$, a gas pressure of $6 \mathrm{psi}$, a pump flow rate of $120 \mu \mathrm{l} / \mathrm{min}$, a nozzle velocity of $1100 \mathrm{~mm} / \mathrm{min}$, and 2 $\mathrm{mm}$ track spacing and with four passes.

The MALDI-MSI experiments were performed using an ultrahigh mass resolution Fourier-transform ion cyclotron resonance mass spectrometer (Solarix 7T $2 \omega$, Bruker Daltonics) equipped with a Smartbeam II $2 \mathrm{kHZ}$ laser and operated in positive mode (Hulme et al., 2020). The laser power was optimized for the experiment. At each sampling position, 150 laser shots were used to acquire data in a range of $\mathrm{m} / \mathrm{z} 500$ 5400 and a lateral resolution of $100 \mu \mathrm{m}$ was used. The method was calibrated using red phosphorous and internally calibrated using a lock mass during the experiment. MALDI-MSI data were visualized using FlexImaging and normalized against root mean square of all data points (Bruker Daltonics, version 5.0).

For statistical analysis of MALDI-MSI data, SCiLS Lab (version 2019b, Bruker Daltonics) was used to export the maximum intensity value for each neuropeptide from the average spectrum generated for each brain ROIs.

Drugs. L-DOPA (Madopar, Roche, Levodopa/carbidopa, ratio $4: 1$, p.o. by gavage) and amantadine (Sigma Millipore, $20 \mathrm{mg} / \mathrm{kg}$; p.o. by gavage) were freshly prepared in water. Cyprodime $(10 \mathrm{mg} / \mathrm{kg}$, Carbosynth), ADC-02520849 (3 mg/kg, Curis), and ADC 02265510 $(3 \mathrm{mg} / \mathrm{kg}$, Curis) were dissolved in $10 \% \mathrm{DMSO} / 90 \%$ water and given orally, or intracerebrally in a $15 \mu \mathrm{g} / \mu \mathrm{l}$ solution. The selected doses were based on a pharmacokinetics study conducted before the present study in the same macaque monkeys. L-DOPA, $\mu$ opioid agents, and amantadine (Stanley et al., 2018) were given simultaneously.

Experimental schedule. Oral and intracerebral treatments were pseudo-randomized with the oral treatments coming first and the intracerebral ones coming later. Intracerebral administrations were performed as previously described (Bezard et al., 1997). Bilateral striatal $(15 \mu \mathrm{l}$ per hemisphere, $15 \mu \mathrm{g} / \mu \mathrm{l}, 3 \mu \mathrm{l} / \mathrm{min})$ or pallidal $(5 \mu \mathrm{l}$ per hemisphere, $15 \mu \mathrm{g} / \mu \mathrm{l}, 2 \mu \mathrm{l} / \mathrm{min}$ ) injections of the $\mu$ opioid receptor ligands were performed through an injection cannula (Plastics One; 28-gauge, $30 \mathrm{~mm}$ length) using a micropump (Pump 22, Harvard Apparatus). Injection cannulae were placed into the guide cannulae for each injection and removed $10 \mathrm{~min}$ after.

Behavioral assessment. Drugs were administered in a restraining chair. The animals were immediately transferred to an observation cage
Table 1. Affinity of the three ligands for opioid receptors

\begin{tabular}{lccc}
\hline & ADC-02520849 & ADC-02265510 & Cyprodime HCl \\
\hline$\mu$ Ki (nM) & 1.2 & 4.0 & 10.6 \\
$\delta$ Ki (nM) & $>1000$ & 160 & 414 \\
K Ki (nM) & 930 & 620 & 109 \\
$\mu / \delta$ selectivity & $>800$ & 160 & 39 \\
$\mu / \kappa$ selectivity & 775 & 155 & 10 \\
\hline
\end{tabular}

(dimensions: $1.1 \mathrm{~m} \times 1.5 \mathrm{~m} \times 1.1 \mathrm{~m}$ ), and behavior was recorded for $240 \mathrm{~min}$ (oral route) or $110 \mathrm{~min}$ (intracerebral route) as per guidelines (Fox et al., 2012) and as previously described (Bezard et al., 2003; Ahmed et al., 2010; Fasano et al., 2010; Porras et al., 2012). A behavioral analyst blinded to treatment conditions scored each animal for (1) parkinsonian motor signs according to an established nonparametric rating scale for range of movement (motor), bradykinesia, posture, and tremor (Ko et al., 2014, 2017); and (2) severity of dyskinesia using the Dyskinesia Disability Scale (Fox et al., 2012): 0, dyskinesia absent; 1, mild, fleeting, and rare dyskinetic postures and movements; 2 , moderate, more prominent abnormal movements, but not interfering significantly with normal behavior; 3 , marked, frequent and, at times, continuous dyskinesia intruding on the normal repertoire of activity; or 4, severe, virtually continuous dyskinetic activity replacing normal behavior and disabling to the animal. "Good on-time" was calculated on a linear scale for the periods when bradykinesia was absent and when scores for chorea and dystonia were absent, mild, or moderate (Fox et al., 2012).

Experimental design and statistical analysis. The study consisted of an in vitro pharmacology study performed on recombinant opioid receptors, followed by an anatomo-pathologic MALDI-MSI study performed on normal, parkinsonian (MPTP) and dyskinetic parkinsonian (L-DOPA-MPTP) macaque monkeys, and subsequently an in vivo pharmacology study in normal, parkinsonian (MPTP) and dyskinetic parkinsonian (L-DOPA-MPTP) macaque monkeys adopting a pseudorandomized crossover design in which all 3 animals received all systemic and intracerebral treatments. GraphPad Prism (version 8.4.2, GraphPad Software) was used to perform statistics, including $\mathrm{EC}_{50}$ definition. MALDI-MSI data were analyzed using a Kruskal-Wallis test followed by a Dunn's multiple comparisons test. Because of the limited number of animals involved in in vivo pharmacology study, results were not corrected for multiple comparisons. After transformation of nonparametric time courses into the parametric area under the curve, data were analyzed using paired $t$ test. Data are presented as mean \pm SEM.

\section{Results}

We first characterized the opioid receptor binding affinity (Table 1 ) as well as the $\mu$ opioid receptor functional profile of experimental ligands, including cyprodime (Fig. 1). Since both systemically administered $\mu$ opioid receptor agonists (Samadi et al., 2004) and thought-to-be antagonists (Henry et al., 1999; Koprich et al., 2011; Potts et al., 2015) had been reported to reduce LID, we aimed at selecting three compounds with a preferential affinity for the $\mu$ opioid receptor compared with the $\kappa$ or $\delta$ opioid receptors (Table 1), defined from binding on $\mu, \kappa$, and $\delta$ opioid receptors-expressing $\mathrm{CHO}$ cells. ADC-02265510 presented clearcut agonist $\left(\mathrm{EC}_{50}=4.43^{-10} \mathrm{M}\right.$; Fig. $\left.1 A\right)$ and ADC-02520849 significant antagonist $\left(\mathrm{IC}_{50}=1.86^{-9} \mathrm{M}\right.$; Fig. $\left.1 B\right)$ activities in a cAMP-based homogeneous time-resolved fluorescence assay conducted on human recombinant $\mu$ opioid receptor-expressing CHO cells (CEREP; Study \#100013735). Cyprodime, however, present in the very same assay a mixed profile $\left(\mathrm{EC}_{50}=1.22^{-10} \mathrm{M}\right.$, $\mathrm{IC}_{50}=7.95^{-5} \mathrm{M}$; Fig. $\left.1 A, B\right)$. A small agonist effect is observed at the higher concentration (100 nm; Fig. 1A), in agreement with an in vitro study showing negligible (10\%) agonist activity of cyprodime in the ${ }^{\left[{ }^{[3]}\right.} \mathrm{GTP}_{\gamma} \mathrm{S}$ assay (Marki et al., 1999). In addition, cyprodime weakly inhibits DAMGO stimulation (Fig. 1B). Such 

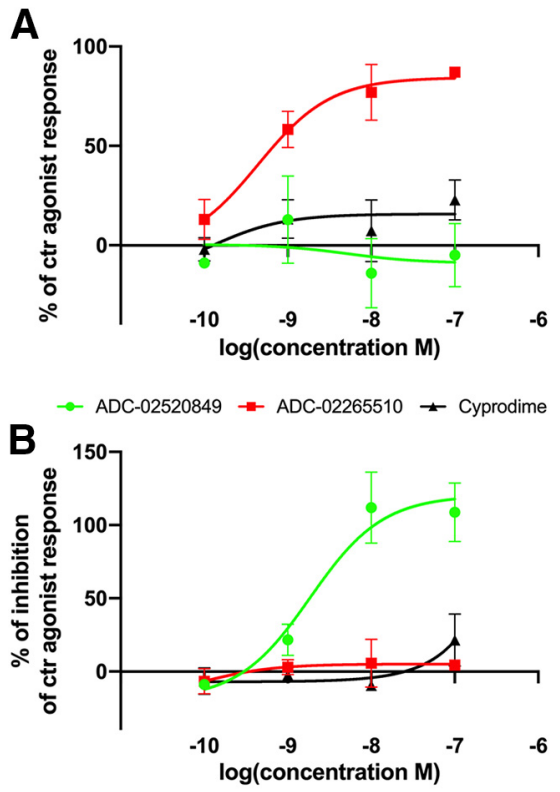

Figure 1. Functional homogeneous time-resolved fluorescence assay on recombinant $\mu$ receptor of ADC-02520849 (green), ADC-02265510 (red), and cyprodime (black). A, Percentage of cAMP-induced control (ctr) DAMGO agonist response. $\boldsymbol{B}$, Percentage of cAMPinduced inhibition of control (ctr) DAMGO agonist response. Experiments were replicated 3 times. Data points are mean \pm SD. Curves indicate nonlinear fit using the standard slope model.

low cyprodime antagonist activity could result from the fact that, in the range of concentrations tested (up to $100 \mathrm{~nm}$ ), the $\mu$ receptor blockade provided by cyprodime was too low to counteract the stimulation induced by $20 \mu \mathrm{M}$ DAMGO. Indeed, only $10 \mu \mathrm{M}$ cyprodime was able to counteract the effect of morphine in vitro (Marki et al., 1999), in contradiction to the original characterization performed before the receptor cloning era (Schmidhammer et al., 1989). We therefore propose, in view of the small agonist activity of cyprodime and the weak antagonist profile at different doses, that cyprodime is actually a weak partial agonist, that is, a compound with a weak agonist activity in an environment of low opioid tone and a weak antagonist in a higher opioid tone environment.

Since previous studies had been performed in NHP MPTP models of PD (Henry et al., 2001; Samadi et al., 2004; Koprich et al., 2011; Potts et al., 2015), we performed the in vivo pharmacology experiments to test the potential effects of the three compounds in the same model (Bezard et al., 2003; Ahmed et al., 2010; Fasano et al., 2010; Porras et al., 2012; Shen et al., 2015; Urs et al., 2015; Baufreton et al., 2018), considered the most clinically relevant model for dyskinesia studies since it very closely mimics the LIDs observed in human patients (Fox et al., 2012; Bastide et al., 2015; Stanley et al., 2018). Experimental details are described in Materials and Methods (Bezard et al., 2003; Ahmed et al., 2010; Fasano et al., 2010; Porras et al., 2012; Shen et al., 2015; Urs et al., 2015; Baufreton et al., 2018).

Before conducting the behavioral experiments, we investigated the actual presence of modified opioid tone in the basal ganglia of dyskinetic MPTP-lesioned macaque monkeys compared with control unlesioned and MPTP-lesioned ones (Fig. $2 A$ ) using brain tissue MALDI-MSI of peptides (Hulme et al., 2020). The endogenous opioids, [Met5]-enkephalin, [Leu5]-enkephalin, $\beta$-endorphin, and truncated forms of dynorphin [e.g., dynorphin $\mathrm{A}(1-9)$ and dynorphin $\mathrm{A}(10-17)$ ] also have affinities for $\mu$ receptors that are consistent with a possible role for each of these peptides as natural ligands for this receptor type, although these endogenous peptides are not selective for $\mu$ receptors (IUPHAR/BPS Guide to Pharmacology). Among those peptides, met-enkephalin, dynorphin A(1-8), and dynorphin A(10-17) are thought to be differentially regulated in parkinsonian and dyskinetic monkeys (Bastide et al., 2015). Met-enkephalin, significantly detected in the GPe but not in the GPi of control, parkinsonian, and dyskinetic animals, did not show an upregulated presence in the GPe or GPi of dyskinetic monkeys (GPe: $\mathrm{KW}_{(2,17)}=0.78, p=0.69$; Fig. $\left.2 B\right)$. However, dynorphin $\mathrm{A}(1-8)$ and dynorphin $\mathrm{A}(10-17)$, two nonspecific ligands of $\mu$ receptors, were notably enhanced in the $\mathrm{ON}$ dyskinesia situation, as expected, in the GPi and SNr of dyskinetic animals (GPi: dynorphin $\mathrm{A}(1-8) \mathrm{KW}_{(2,17)}=7.03, p=0.022$; dynorphin $\mathrm{A}(10-17)$ $\mathrm{KW}_{(2,17)}=6.0, p=0.042$; Fig. $\left.2 C, D\right)$, indicative of a heightened tone in these structures, in accordance with previous reports on both peptide precursors mRNA and opioid peptide levels (Aubert et al., 2007; Bourdenx et al., 2014). The preferred $\kappa$ ligand, dynorphin, is thus the sole $\mu$ receptor ligand heavily represented in the GPi of dyskinetic monkeys.

Three dyskinetic MPTP-lesioned macaque monkeys were bilaterally cannulated under stereotactic guidance (Bezard et al., 1997; Boraud et al., 2001; Porras et al., 2014; Engeln et al., 2016) to permit intracerebral injection into the motor striatum (putamen) and the GPi. The behavior of the animals was investigated after oral or intracerebral administrations, in combination with oral L-DOPA. Since the only clinically recommended antidyskinetic agent is amantadine, a multitarget drug with antagonistic activity at the NMDA receptor (Verhagen Metman et al., 1998; Fox et al., 2011), we used amantadine as a benchmark systemic antidyskinetic therapy in the dyskinetic macaques (Stanley et al., 2018), which all showed a significant reduction in LID severity when given L-DOPA+ amantadine compared with L-DOPA + vehicle $(t=13.0, \mathrm{df}=2, p=0.006$; Fig. $3 A, B)$ without affecting the antiparkinson activity of LDOPA (Fig. $3 C$ ) as previously described (Stanley et al., 2018). Interestingly, while neither the partial agonist cyprodime nor the antagonist ADC-02520849 was able to diminish LID severity after systemic administration, the combination of L-DOPA and the agonist ADC-02265510 did reduce LID severity ( $t=16.5$, df $=2, p=0.0036$; Fig. $3 A, B)$, without affecting the antiparkinson activity of L-DOPA (Fig. $3 C$ ), thereby dramatically improving "good on-time" (i.e., the time spent being turned ON without disabling dyskinesia).

The same dyskinetic MPTP-lesioned macaque monkeys then received drug administration into the striatum or GPi in combination with oral L-DOPA. Neither intrastriatal (Fig. 3D,E) nor GPi (Fig. 3G,H) administration of the antagonist ADC-02520849 had an impact on LID severity. LID was transiently improved after intrastriatal administration of the partial agonist cyprodime $(t=4.9, \mathrm{df}=2, p=0.038$ over the entire time course; Fig. $3 D, E)$ but not after injection into GPi (Fig. $3 G, H$ ). In contrast, both intrastriatal $(t=21.0, \mathrm{df}=2, p=0.0023$; Fig. $3 D, E)$ and $\mathrm{GPi}$ $(t=22.3, \mathrm{df}=2, p=0.002$; Fig. $3 G, H)$ administration of the agonist ADC-02265510 significantly reduced LID severity, without affecting the antiparkinson activity of L-DOPA (Fig. 3F,I).

\section{Discussion}

The mainstay of PD motor symptom therapy since the 1970s has been the dopamine precursor L-DOPA (Carlsson et al., 1957; Birkmayer and Hornykiewicz, 1962) and will likely remain so until better therapies are developed. A rational approach to the 
development of novel antidyskinetic pharmacotherapies should first identify and then exploit the biology of L-DOPAinduced dyskinesia. The present data strongly suggest that only the $\mu$ opioid receptor agonist was capable of alleviating LID impairment after being administered orally, intrastriatally, or into the GPi with a magnitude possibly surpassing the antidyskinetic benchmark amantadine.

Dopamine neurones progressively degenerate in PD, thus depriving dopamine receptors expressed by striatal medium spiny neurones of their endogenous ligand, enabling the dysregulation of opioid precursors and, eventually, of opioid peptide cotransmitters in the same striatal medium spiny neurons (Bastide et al., 2015). This heightened opioid tone, particularly important in the pallidal complex where medium spiny neurones project (Nadjar et al., 2006) (Fig. 2), is thought to underlie, at least in part, the etiology of dyskinesias by dysregulated control of GABA neurotransmitter release in the pallidal complex (Bastide et al., 2015). LID was originally hypothesized to be caused by abnormally reduced firing frequency, and dysregulated discharge pattern, of the GPi (Crossman, 1987, 1990; Albin et al., 1989; DeLong, 1990), a proposal later confirmed in dyskinetic MPTP-treated macaque monkeys (Filion et al., 1991; Papa et al., 1999; Boraud et al., 2001) and in PD patients (Merello et al., 1999; Levy et al., 2001; Lee et al., 2007). $\mu$ opioid receptors are expressed on GABAergic terminals of medium spiny neurones in the pallidal complex (Mansour et al., 1995; Ding et al., 1996) and control GABA release (Maneuf et al., 1996; Stanford and Cooper, 1999). A $\mu$ opioid receptor ligand would thus serve to reduce GABA release in the pallidal complex. In the context of LID, where GPi firing frequency is abnormally reduced, presumably in part because of enhanced GABAergic tone from the direct pathway medium spiny neurones and from a decreased subthalamic nucleus drive ending the indirect pathway (Bastide et al., 2015), one might logically attempt to stimulate $\mu$ opioid receptors to dampen the GABA release instead of antagonizing them. We propose that the LIDassociated enhanced opioid tone in the basal ganglia actually represents a failed adaptive mechanism that aims to maintain a proper firing behavior of the GPi. It obviously fails as in LID (1) the GPi firing frequency is abnormally reduced and (2) patients display hyperkinetic movements.

Intrastriatal administration of a $\mu$ opioid receptor agonist leads to dyskinesia alleviation. The mechanism of action is likely to be more complex than that of the effect of administration into the GPi as $\mu$ opioid receptors are expressed in the striatum (1) at a presynaptic level by cortical afferents (where it could regulate glutamate release) and at a postsynaptic level by (2) both direct and indirect striatofugal neurones as well as by (3) the cholinergic interneurones (Sgroi and Tonini, 2018). While changes in the electrophysiological activity of cortical afferents in LID is still a matter of debate (Bastide et al., 2015), that a $\mu$ opioid receptor agonist can dampen the activity of striatofugal neurones may actually lead to a synergistic normalization of the activity of the basal ganglia output structures (Sgroi and Tonini, 2018). Interestingly, the documented impact of $\mu$ opioid receptor agonism on D2 dopamine receptor-mediated transmission (Mamaligas et al., 2016; Sgroi and Tonini, 2018) provides an explanatory framework by which a $\mu$ opioid receptor agonist would allow normalizing the activity of the dyskinesia-related overinhibited indirect pathway striatofugal D2-expressing neurones.

In line with this concept of failed compensatory mechanism is the observation that, while further agonistic stimulation of $\mu$ opioid receptor reduces LID (Fig. 3), the partial agonist only transiently improves LID after intrastriatal (but not after systemic or intrapallidal) administration (Fig. 3). Partial agonists are janus-like molecules that can cause either (1) activation of a quiescent system (e.g., in absence of physiological agonist) or (2) 
No L-DOPA

L-DOPA + Vehicle

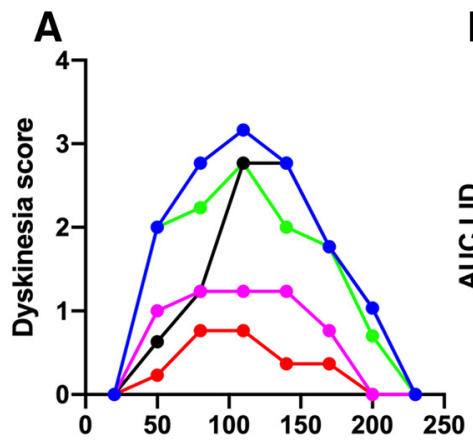

D
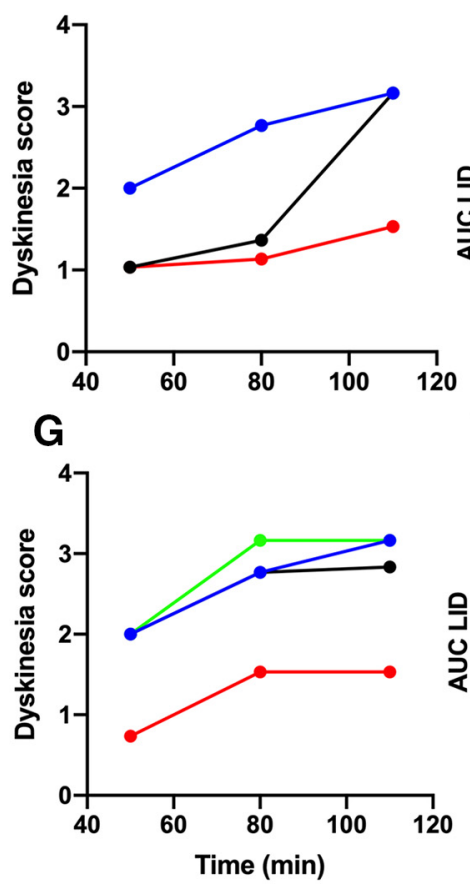

L-DOPA + Amantadine

L-DOPA + Cyprodime

B

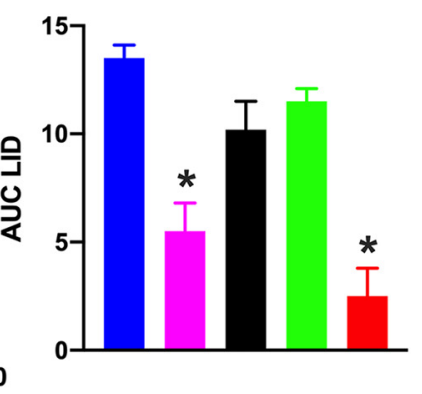

E

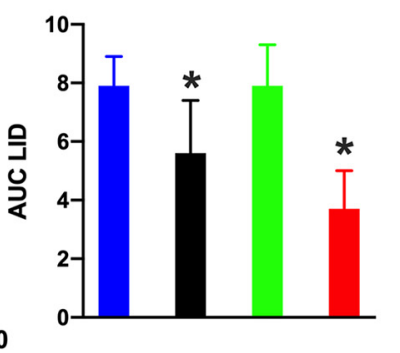

$\mathrm{H}$

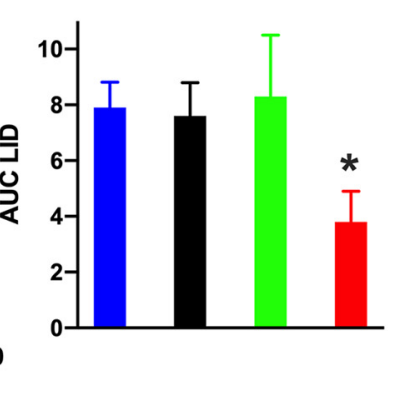

L-DOPA + ADC-02520849

L-DOPA + ADC-02265510

C

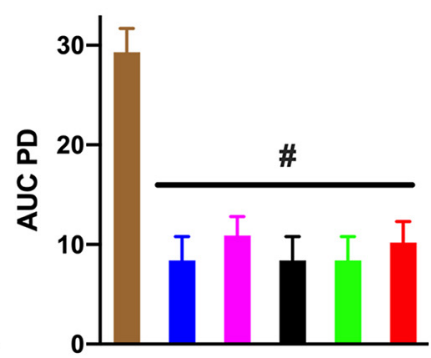

$F$

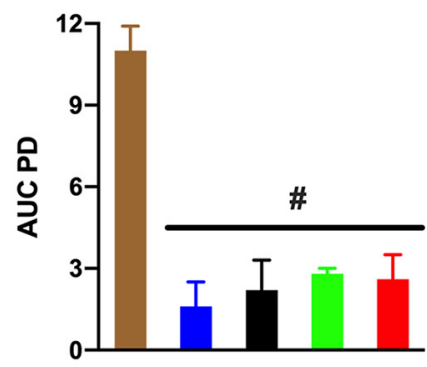

I

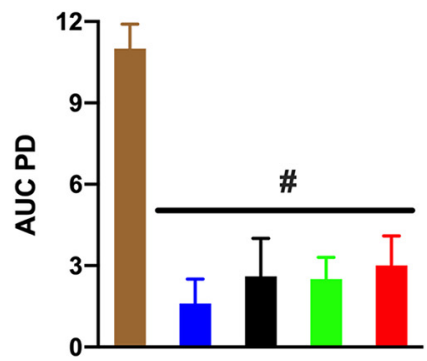

Figure 3. $\mu$ opioid agonist reduces dyskinesia severity in a MPTP macaque PD model. $\boldsymbol{A}, \boldsymbol{D}, \boldsymbol{G}$, Time course of effect since administration. $\boldsymbol{B}, \boldsymbol{E}, \boldsymbol{H}$, Area under the curve of the dyskinesia scores depicted on the left and right. $C, F, I$, Area under the curve of the Parkinson scores. The following treatments were given: the two references treatment: no L-DOPA (brown) and L-DOPA alone (blue); the antidyskinetic benchmark L-DOPA + amantadine (pink), and the three test items L-DOPA + cyprodime (black), L-DOPA+ADC-02520849 (green), and L-DOPA+ADC-02265510 (red). A-C, Oral (systemic) administration of all drugs (amantadine $20 \mathrm{mg} / \mathrm{kg}$; cyprodime $10 \mathrm{mg} / \mathrm{kg}$; ADC-02520849 $3 \mathrm{mg} / \mathrm{kg}$; ADC $022655103 \mathrm{mg} / \mathrm{kg}$ ). D-F, Intrastriatum administration of cyprodime, ADC-02520849, and ADC-02265510 (for all, $15 \mu \mathrm{l}$ per hemisphere at $15 \mu \mathrm{g} / \mu \mathrm{l}$ ) while L-DOPA was given orally. G-I, Intra-GPi administration of cyprodime, ADC-02520849, and ADC02265510 (for all, $5 \mu \mathrm{l}$ per hemisphere at $15 \mu \mathrm{g} / \mu \mathrm{l}$ ) while L-DOPA was given orally. $N=3 .{ }^{*} p<0.05$, all groups compared with L-DOPA alone. ${ }^{*} p<0.05$ compare all groups to no L-DOPA.

antagonism of response in a system activated by a more efficacious agonist (Carlsson, 2001; Pulvirenti and Koob, 2002). We demonstrated the reality of such an elegant pharmacological concept with dopamine D3 receptor pharmacology by showing the antidyskinetic action of a partial D3 receptor agonist acting as an antagonist in the context of a heightened dopamine tone (Bezard et al., 2003). Here we show that a $\mu$ opioid receptor partial agonist, likely acting as an antagonist since the endogenous ligand dynorphin levels are increased, fails to improve LID, as does a full antagonist (Fig. 3).

Although we show that a $\mu$ opioid receptor agonist alleviates LID in the gold standard NHP model of PD and LID, we acknowledge the difficulties posed by agonizing the $\mu$ opioid receptor given the obvious addictive potential. The development of biased ligands at G-protein-coupled receptors in general and $\mu$ opioid receptor in particular is, however, opening new possibilities (Violin et al., 2014). The concept of biased agonism has been elaborated for describing the pharmacological preferential activation of one signaling partner downstream of receptor activation over another (i.e., G-protein activation vs $\beta$-arrestin recruitment) (Kenakin, 2013). The rationale for this stemmed from experiments in $\beta$-arrestin $\mathrm{KO}$ mice, where $\mu$ opioid receptor activation produced analgesia, but significantly less side effects associated with opioid administration, including constipation, respiratory depression, and tolerance (Bohn et al., 1999). Therefore, significant efforts have been placed on designing ligands biased toward G-protein activation, a requirement for analgesic efficacy, while avoiding interaction with $\beta$-arrestin. Clinical studies showing that biased opioid agonists could yield safer pain relief while protecting, notably, breathing (Urits et al., 2019), raises the possibility that LID might be treated with a biased agonist in the absence of addiction. 
The present results suggest a reappraisal of our interpretation of the role of the opioid cotransmitters in the pathophysiology of basal ganglia, reconciling previously conflicting concepts, through the demonstration that a $\mu$ opioid receptor agonist, and not an antagonist, alleviates LID.

\section{References}

Ahmed MR, Berthet A, Bychkov E, Porras G, Li Q, Bioulac BH, Carl YT, Bloch B, Kook S, Aubert I, Dovero S, Doudnikoff E, Gurevich VV, Gurevich EV, Bezard E (2010) Lentiviral overexpression of GRK6 alleviates L-dopa-induced dyskinesia in experimental Parkinson's disease. Sci Transl Med 2:28ra28.

Albin RL, Young AB, Penney JB (1989) The functional anatomy of basal ganglia disorders. Trends Neurosci 12:366-375.

Aubert I, Guigoni C, Hakansson K, Li Q, Dovero S, Barthe N, Bioulac BH, Gross CE, Fisone G, Bloch B, Bezard E (2005) Increased D1 dopamine receptor signaling in levodopa-induced dyskinesia. Ann Neurol 57:17-26.

Aubert I, Guigoni C, Li Q, Dovero S, Bioulac BH, Gross CE, Crossman AR, Bloch B, Bezard E (2007) Enhanced preproenkephalin-B-derived opioid transmission in striatum and subthalamic nucleus converges upon globus pallidus internalis in L-dopa-induced dyskinesia. Biol Psychiatry 61:836-844.

Bastide MF, Meissner WG, Picconi B, Fasano S, Fernagut PO, Feyder M, Francardo V, Alcacer C, Ding Y, Brambilla R, Fisone G, Stoessl AJ, Bourdenx M, Engeln M, Navailles S, De Deurwaerdère P, Ko WK, Simola N, Morelli M, Groc L, et al. (2015) Pathophysiology of L-dopa-induced motor and non-motor complications in Parkinson's disease. Prog Neurobiol 132:96-168.

Baufreton J, Milekovic T, Li Q, McGuire S, Moraud EM, Porras G, Sun S, Ko WK, Chazalon M, Morin S, Normand E, Farjot G, Milet A, Pype J, Pioli E, Courtine G, Bessiere B, Bezard E (2018) Inhaling xenon ameliorates Ldopa-induced dyskinesia in experimental parkinsonism. Mov Disord 33:1632-1642.

Bezard E, Boraud T, Bioulac B, Gross CE (1997) Compensatory effects of glutamatergic inputs to the substantia nigra pars compacta in experimental parkinsonism. Neuroscience 81:399-404.

Bezard E, Ferry S, Mach U, Stark H, Leriche L, Boraud T, Gross C, Sokoloff P (2003) Attenuation of levodopa-induced dyskinesia by normalizing dopamine D3 receptor function. Nat Med 9:762-767.

Bezard E, Brotchie JM, Gross CE (2001a) Pathophysiology of levodopa-induced dyskinesia: potential for new therapies. Nat Rev Neurosci 2:577-588.

Bezard E, Dovero S, Prunier C, Ravenscroft P, Chalon S, Guilloteau D, Crossman AR, Bioulac B, Brotchie JM, Gross CE (2001b) Relationship between the appearance of symptoms and the level of nigrostriatal degeneration in a progressive 1-methyl-4-phenyl-1,2,3,6-tetrahydropyridine-lesioned macaque model of Parkinson's disease. J Neurosci 21:6853-6861.

Birkmayer W, Hornykiewicz O (1962) [The L-dihydroxyphenylalanine (LDOPA) effect in Parkinson's syndrome in man: on the pathogenesis and treatment of Parkinson akinesis]. Arch Psychiatr Nervenkr Z Gesamte Neurol Psychiatr 203:560-574.

Bohn LM, Lefkowitz RJ, Gainetdinov RR, Peppel K, Caron MG, Lin FT (1999) Enhanced morphine analgesia in mice lacking beta-arrestin 2. Science 286:2495-2498.

Boraud T, Bezard E, Bioulac B, Gross CE (2001) Dopamine agonist-induced dyskinesias are correlated to both firing pattern and frequency alterations of pallidal neurones in the MPTP-treated monkey. Brain 124:546-557.

Bourdenx M, Nilsson A, Wadensten H, Falth M, Li Q, Crossman AR, Andren PE, Bezard E (2014) Abnormal structure-specific peptide transmission and processing in a primate model of Parkinson's disease and LDOPA-induced dyskinesia. Neurobiol Dis 62:307-312.

Carlsson A (2001) A paradigm shift in brain research. Science 294:10211024.

Carlsson A, Lindqvist M, Magnusson T (1957) 3,4-Dihydroxyphenylalanine and 5-hydroxytryptophan as reserpine antagonists. Nature 180:1200.

Cenci MA, Lee CS, Bjorklund A (1998) L-DOPA-induced dyskinesia in the rat is associated with striatal overexpression of prodynorphin- and glutamic acid decarboxylase mRNA. Eur J Neurosci 10:2694-2706.

Crossman AR (1987) Primate models of dyskinesia: the experimental approach to the study of basal ganglia-related involuntary movement disorders. Neuroscience 21:1-40.

Crossman AR (1990) A hypothesis on the pathophysiological mechanisms that underlie levodopa- or dopamine agonist-induced dyskinesia in
Parkinson's disease: implications for future strategies in treatment. Mov Disord 5:100-108.

DeLong MR (1990) Primate models of movement disorders of basal ganglia origin. Trends Neurosci 13:281-285.

Ding YQ, Kaneko T, Nomura S, Mizuno N (1996) Immunohistochemical localization of mu-opioid receptors in the central nervous system of the rat. J Comp Neurol 367:375-402.

Engeln M, De Deurwaerdere P, Li Q, Bezard E, Fernagut PO (2015) Widespread monoaminergic dysregulation of both motor and non-motor circuits in parkinsonism and dyskinesia. Cereb Cortex 25:2783-2792.

Engeln M, Bastide MF, Toulme E, Dehay B, Bourdenx M, Doudnikoff E, Li Q, Gross CE, Boue-Grabot E, Pisani A, Bezard E, Fernagut PO (2016) Selective Inactivation of striatal FosB/DeltaFosB-expressing neurons alleviates L-DOPA-induced dyskinesia. Biol Psychiatry 79:354-361.

Eshraghi M, Ramirez-Jarquin UN, Shahani N, Nuzzo T, De Rosa A, Swarnkar S, Galli N, Rivera O, Tsaprailis G, Scharager-Tapia C, Crynen G, Li Q, Thiolat ML, Bezard E, Usiello A, Subramaniam S (2020) RasGRP1 is a causal factor in the development of L-DOPA-induced dyskinesia in Parkinson's disease. Sci Adv 6:eaaz7001.

Fasano S, Bezard E, D’Antoni A, Francardo V, Indrigo M, Qin L, Dovero S, Cerovic M, Cenci MA, Brambilla R (2010) Inhibition of Ras-guanine nucleotide-releasing factor 1 (Ras-GRF1) signaling in the striatum reverts motor symptoms associated with L-dopa-induced dyskinesia. Proc Natl Acad Sci USA 107:21824-21829.

Filion M, Tremblay L, Bedard PJ (1991) Effects of dopamine agonists on the spontaneous activity of globus pallidus neurons in monkeys with MPTPinduced parkinsonism. Brain Res 547:152-161.

Fox SH, Silverdale M, Kellett M, Davies R, Steiger M, Fletcher N, Crossman A, Brotchie J (2004) Non-subtype-selective opioid receptor antagonism in treatment of levodopa-induced motor complications in Parkinson's disease. Mov Disord 19:554-560.

Fox SH, Katzenschlager R, Lim SY, Ravina B, Seppi K, Coelho M, Poewe W, Rascol O, Goetz CG, Sampaio C (2011) The Movement Disorder Society Evidence-Based Medicine Review Update: treatments for the motor symptoms of Parkinson's disease. Mov Disord 26 Suppl 3:S2-S41.

Fox SH, Johnston TH, Li Q, Brotchie J, Bezard E (2012) A critique of available scales and presentation of the Nonhuman Primate Dyskinesia Rating Scale. Mov Disord 27:1373-1378.

François C, Yelnik J, Percheron G (1996) A stereotaxic atlas of the basal ganglia in macaques. Brain Res Bull 41:151-158.

Hanrieder J, Ljungdahl A, Falth M, Mammo SE, Bergquist J, Andersson M (2011) L-DOPA-induced dyskinesia is associated with regional increase of striatal dynorphin peptides as elucidated by imaging mass spectrometry. Mol Cell Proteomics 10:M111.009308.

Henry B, Crossman AR, Brotchie JM (1999) Effect of repeated L-DOPA, bromocriptine, or lisuride administration on preproenkephalin-A and preproenkephalin-B mRNA levels in the striatum of the 6-hydroxydopaminelesioned rat. Exp Neurol 155:204-220.

Henry B, Fox SH, Crossman AR, Brotchie JM (2001) Mu- and delta-opioid receptor antagonists reduce levodopa-induced dyskinesia in the MPTPlesioned primate model of Parkinson's disease. Exp Neurol 171:139-146.

Henry B, Duty S, Fox SH, Crossman AR, Brotchie JM (2003) Increased striatal pre-proenkephalin B expression is associated with dyskinesia in Parkinson's disease. Exp Neurol 183:458-468.

Hulme H, Fridjonsdottir E, Gunnarsdottir H, Vallianatou H, Zhang X, Wadensten H, Shariatgorji M, Nilsson A, Bezard E, Svenningsson P, Andrén PE (2020) Simultaneous mass spectrometry imaging of multiple neuropeptides in the brain and alterations induced by experimental parkinsonism and L-DOPA therapy. Neurobiol Dis 137:104738.

Johansson PA, Andersson M, Andersson KE, Cenci MA (2001) Alterations in cortical and basal ganglia levels of opioid receptor binding in a rat model of L-DOPA-induced dyskinesia. Neurobiol Dis 8:220-239.

Kenakin T (2013) Allosteric drugs and seven transmembrane receptors. Curr Top Med Chem 13:5-13.

Ko WK, Pioli E, Li Q, McGuire S, Dufour A, Sherer TB, Bezard E, Facheris MF (2014) Combined fenobam and amantadine treatment promotes robust antidyskinetic effects in the 1-methyl-4-phenyl-1,2,3,6-tetrahydropyridine (MPTP)-lesioned primate model of Parkinson's disease. Mov Disord 29:772-779.

Ko WK, Li Q, Cheng LY, Morelli M, Carta M, Bezard E (2017) A preclinical study on the combined effects of repeated eltoprazine and preladenant 
treatment for alleviating L-DOPA-induced dyskinesia in Parkinson's disease. Eur J Pharmacol 813:10-16.

Koprich JB, Fox SH, Johnston TH, Goodman A, Le Bourdonnec B, Dolle RE, DeHaven RN, DeHaven-Hudkins DL, Little PJ, Brotchie JM (2011) The selective mu-opioid receptor antagonist ADL5510 reduces levodopa-induced dyskinesia without affecting antiparkinsonian action in MPTP-lesioned macaque model of Parkinson's disease. Mov Disord 26:1225-1233.

Lee JI, Verhagen Metman L, Ohara S, Dougherty PM, Kim JH, Lenz FA (2007) Internal pallidal neuronal activity during mild drug-related dyskinesias in Parkinson's disease: decreased firing rates and altered firing patterns. J Neurophysiol 97:2627-2641.

Levy R, Dostrovsky JO, Lang AE, Sime E, Hutchison WD, Lozano AM (2001) Effects of apomorphine on subthalamic nucleus and globus pallidus internus neurons in patients with Parkinson's disease. J Neurophysiol 86:249-260.

Mamaligas AA, Cai Y, Ford CP (2016) Nicotinic and opioid receptor regulation of striatal dopamine D2-receptor mediated transmission. Sci Rep 6:37834.

Maneuf YP, Duty S, Hille CJ, Crossman AR, Brotchie JM (1996) Modulation of GABA transmission by diazoxide and cromakalim in the globus pallidus: implications for the treatment of Parkinson's disease. Exp Neurol 139:12-16.

Mansour A, Fox CA, Akil H, Watson SJ (1995) Opioid-receptor mRNA expression in the rat CNS: anatomical and functional implications. Trends Neurosci 18:22-29.

Marki A, Monory K, Otvos F, Toth G, Krassnig R, Schmidhammer H, Traynor JR, Roques BP, Maldonado R, Borsodi A (1999) Mu-opioid receptor specific antagonist cyprodime: characterization by in vitro radioligand and [35S] GTPgammaS binding assays. Eur J Pharmacol 383:209-214.

Marti M, Rodi D, Li Q, Guerrini R, Fasano S, Morella I, Tozzi A, Brambilla R, Calabresi P, Simonato M, Bezard E, Morari M (2012) Nociceptin/ orphanin FQ receptor agonists attenuate L-DOPA-induced dyskinesias. J Neurosci 32:16106-16119.

Mellone M, Zianni E, Stanic J, Campanelli F, Marino G, Ghiglieri V, Longhi A, Thiolat ML, Li Q, Calabresi P, Bezard E, Picconi B, Di Luca M, Gardoni F (2019) NMDA receptor GluN2D subunit participates to levodopa-induced dyskinesia pathophysiology. Neurobiol Dis 121:338-349.

Mercatelli D, Bezard E, Eleopra R, Zaveri NT, Morari M (2020) Managing Parkinson's disease: moving ON with NOP. Br J Pharmacol 177:28-47.

Merello M, Balej J, Delfino M, Cammarota A, Betti O, Leiguarda R (1999) Apomorphine induces changes in GPi spontaneous outflow in patients with Parkinson's disease. Mov Disord 14:45-49.

Morissette M, Grondin R, Goulet M, Bedard PJ, Di Paolo T (1999) Differential regulation of striatal preproenkephalin and preprotachykinin mRNA levels in MPTP-lesioned monkeys chronically treated with dopamine D-1 or D-2 receptor agonists. J Neurochem 72:682-692.

Nadjar A, Brotchie JM, Guigoni C, Li Q, Zhou SB, Wang GJ, Ravenscroft P, Georges F, Crossman AR, Bezard E (2006) Phenotype of striatofugal medium spiny neurons in parkinsonian and dyskinetic nonhuman primates: a call for a reappraisal of the functional organization of the basal ganglia. J Neurosci 26:8653-8661.

Napolitano F, Booth Warren E, Migliarini S, Punzo D, Errico F, Li Q, Thiolat ML, Vescovi AL, Calabresi P, Bezard E, Morelli M, Konradi C, Pasqualetti M, Usiello A (2017) Decreased Rhes mRNA levels in the brain of patients with Parkinson's disease and MPTP-treated macaques. PLoS One 12:e0181677.

Papa SM, Desimone R, Fiorani M, Oldfield EH (1999) Internal globus pallidus discharge is nearly suppressed during levodopa-induced dyskinesias. Ann Neurol 46:732-738.

Parent A, Cote PY, Lavoie B (1995) Chemical anatomy of primate basal ganglia. Prog Neurobiol 46:131-197.

Piccini P, Weeks RA, Brooks DJ (1997) Alterations in opioid receptor binding in Parkinson's disease patients with levodopa-induced dyskinesias. Ann Neurol 42:720-726.

Porras G, Berthet A, Dehay B, Li Q, Ladepeche L, Normand E, Dovero S, Martinez A, Doudnikoff E, Martin-Negrier ML, Chuan Q, Bloch B, Choquet D, Boue-Grabot E, Groc L, Bezard E (2012) PSD-95 expression controls L-DOPA dyskinesia through dopamine D1 receptor trafficking. J Clin Invest 122:3977-3989.

Porras G, De Deurwaerdere P, Li Q, Marti M, Morgenstern R, Sohr R, Bezard E, Morari M, Meissner WG (2014) L-dopa-induced dyskinesia: beyond an excessive dopamine tone in the striatum. Sci Rep 4:3730.
Potts LF, Park ES, Woo JM, Dyavar Shetty BL, Singh A, Braithwaite SP, Voronkov M, Papa SM, Mouradian MM (2015) Dual kappa-agonist/muantagonist opioid receptor modulation reduces levodopa-induced dyskinesia and corrects dysregulated striatal changes in the nonhuman primate model of Parkinson disease. Ann Neurol 77:930-941.

Pulvirenti L, Koob GF (2002) Being partial to psychostimulant addiction therapy. Trends Pharmacol Sci 23:151-153.

Rascol O, Fabre N, Blin O, Poulik J, Sabatini U, Senard JM, Ane M, Montastruc JL, Rascol A (1994) Naltrexone, an opiate antagonist, fails to modify motor symptoms in patients with Parkinson's disease. Mov Disord 9:437-440

Rojo-Bustamante E, Abellanas MA, Clavero P, Thiolat ML, Li Q, Luquin MR, Bezard E, Aymerich MS (2018) The expression of cannabinoid type 1 receptor and 2-arachidonoyl glycerol synthesizing/degrading enzymes is altered in basal ganglia during the active phase of levodopa-induced dyskinesia. Neurobiol Dis 118:64-75.

Rylander D, Parent M, O'Sullivan SS, Dovero S, Lees AJ, Bezard E, Descarries L, Cenci MA (2010) Maladaptive plasticity of serotonin axon terminals in levodopa-induced dyskinesia. Ann Neurol 68:619-628.

Samadi P, Gregoire L, Bedard PJ (2004) The opioid agonist morphine decreases the dyskinetic response to dopaminergic agents in parkinsonian monkeys. Neurobiol Dis 16:246-253.

Santini E, Sgambato-Faure V, Li Q, Savasta M, Dovero S, Fisone G, Bezard E (2010) Distinct changes in cAMP and extracellular signal-regulated protein kinase signalling in L-DOPA-induced dyskinesia. PLoS One 5:e12322.

Schmidhammer H, Burkard WP, Eggstein-Aeppli L, Smith CF (1989) Synthesis and biological evaluation of 14-alkoxymorphinans: 2. (-)-N(cyclopropylmethyl)-4,14-dimethoxymorphinan-6-one, a selective mu opioid receptor antagonist. J Med Chem 32:418-421.

Sgroi S, Tonini R (2018) Opioidergic modulation of striatal circuits: implications in Parkinson's disease and levodopa induced dyskinesia. Front Neurol 9:524.

Shariatgorji M, Nilsson A, Goodwin RJ, Kallback P, Schintu N, Zhang X, Crossman AR, Bezard E, Svenningsson P, Andren PE (2014) Direct targeted quantitative molecular imaging of neurotransmitters in brain tissue sections. Neuron 84:697-707.

Shariatgorji M, Nilsson A, Fridjonsdottir E, Vallianatou T, Kallback P, Katan L, Savmarker J, Mantas I, Zhang X, Bezard E, Svenningsson P, Odell LR, Andren PE (2019) Comprehensive mapping of neurotransmitter networks by MALDI-MS imaging. Nat Methods 16:1021-1028.

Shen W, Plotkin JL, Francardo V, Ko WK, Xie Z, Li Q, Fieblinger T, Wess J, Neubig RR, Lindsley CW, Conn PJ, Greengard P, Bezard E, Cenci MA, Surmeier DJ (2015) M4 muscarinic receptor signaling ameliorates striatal plasticity deficits in models of L-DOPA-induced dyskinesia. Neuron 88:762-773.

Stanford IM, Cooper AJ (1999) Presynaptic mu and delta opioid receptor modulation of GABAA IPSCs in the rat globus pallidus in vitro. J Neurosci 19:4796-4803.

Stanley P, Pioli EY, Kozak R, Popiolek M, Bezard E (2018) Meta-analysis of amantadine efficacy for improving preclinical research reliability. Mov Disord 33:1555-1557.

Tel BC, Zeng BY, Cannizzaro C, Pearce RK, Rose S, Jenner P (2002) Alterations in striatal neuropeptide mRNA produced by repeated administration of L-DOPA, ropinirole or bromocriptine correlate with dyskinesia induction in MPTP-treated common marmosets. Neuroscience 115:1047-1058.

Urits I, Viswanath O, Orhurhu V, Gress K, Charipova K, Kaye AD, Ngo A (2019) The utilization of mu-opioid receptor biased agonists: oliceridine, an opioid analgesic with reduced adverse effects. Curr Pain Headache Rep 23:31.

Urs NM, Bido S, Peterson SM, Daigle TL, Bass CE, Gainetdinov RR, Bezard E, Caron MG (2015) Targeting beta-arrestin2 in the treatment of LDOPA-induced dyskinesia in Parkinson's disease. Proc Natl Acad Sci USA 112:2517-2526.

Verhagen Metman L, Del Dotto P, van den Munckhof P, Fang J, Mouradian MM, Chase TN (1998) Amantadine as treatment for dyskinesias and motor fluctuations in Parkinson's disease. Neurology 50:1323-1326.

Violin JD, Crombie AL, Soergel DG, Lark MW (2014) Biased ligands at Gprotein-coupled receptors: promise and progress. Trends Pharmacol Sci 35:308-316. 